\title{
Atypical adenomatous hyperplasia of the lung: a clinicopathological study of 118 cases including cases with multiple atypical adenomatous hyperplasia
}

\author{
R Nakahara, T Yokose, K Nagai, Y Nishiwaki, A Ochiai
}

\begin{abstract}
Background-Atypical adenomatous hyperplasia (AAH) of the lung is a putative precursor lesion of adenocarcinoma, according to many immunohistochemical and genetical studies, but few clinicopathological studies on a large number of cases have been reported. The aim of this study was to clarify the clinicopathological characteristics of lung cancer patients with AAH lesions.
\end{abstract}

Methods-A retrospective study was carried out on 508 consecutive primary lung cancer patients operated on at National Cancer Center Hospital East. The relationship between the number and location of AAH lesions and the clinicopathological features of the lung cancer patients was analysed statistically.

Results-A total of 311 AAH lesions were found in $118(23.2 \%)$ of the 508 cases. AAH lesions were detected in 121 of 572 lobes examined, usually in both upper lobes, and occurred most frequently in patients with adenocarcinoma (OR 2.97; 95\% CI 1.82 to 4.85 ). AAH lesions were more frequently detected in patients with multiple primary carcinomas than in those with a single carcinoma (OR 3.06; 95\% CI 1.56 to 6.00 ). The presence of AAH lesions was not significantly correlated with sex, age, smoking status, familial history of malignancy, or preceding malignancy. Patients with multiple AAH lesions were found to have a significantly higher frequency of preceding malignancies.

Conclusions-The present study highlights the clinicopathological characteristics of AAH lesions, showing them to be significantly associated with both adenocarcinoma and multiple primary carcinoma of the lung and suggesting common factors in the histogenesis of multiple AAH lesions and preceding malignancy. (Thorax 2001;56:302-305)

Keywords: atypical adenomatous hyperplasia; lung cancer; precancerous conditions

Atypical adenomatous hyperplasia (AAH) is a solitary lesion in which atypical bronchioloalveolar cuboidal cells proliferate along the alveolar septa. The morphological similarity between AAH and bronchioloalveolar carcinoma (BAC) suggested the hypothesis that
AAH is a precursor lesion of BAC..$^{1-6}$ Recent molecular genetic analyses demonstrating that some genetic abnormalities frequently detected in BAC are also observed in AAH suggest an AAH-BAC sequence in the carcinogenic pathway. ${ }^{4-10}$

The number of AAH lesions detected dramatically increased after the introduction of helical computed tomographic (CT) health check ups in Japan, ${ }^{11}$ and cases of multiple AAH lesions have also frequently been found. ${ }^{12}$ However, fewer clinicopathological studies have been conducted on cases of AAH. ${ }^{13}{ }^{14} \mathrm{We}$ previously reported a study of 137 cases of AAH in which we found no significant correlation between the presence of AAH lesions and the outcome of patients with lung cancer. ${ }^{15}$ Based on that study, we decided to investigate the background of $\mathrm{AAH}$, especially multiple $\mathrm{AAH}$ lesions, in greater detail. The aim of the present study was therefore to clarify the detailed clinicopathological characteristics of lung cancer patients with AAH lesions in more than 100 cases.

\section{Methods}

Between January 1995 and July 1998508 patients underwent resection of primary lung carcinoma at the National Cancer Center Hospital East. Cases of partial resection and segmentectomy of the main tumour were excluded from the study. The lung cancers were histologically typed according to the World Health Organization classification of lung tumours. ${ }^{16}$

The resected specimens were fixed with $10 \%$ formalin or $99.8 \%$ methanol directly through the bronchial tree or pleura and the specimens were sliced at $5-10 \mathrm{~mm}$ intervals. We first carefully examined the entire surface of the sliced specimens with a loupe and stereoscopic microscope. The slice containing the largest diameter of the main tumour was trimmed into blocks, and any other nodular lesions detected by careful macroscopic observation were also trimmed into blocks. In addition, 1-6 random blocks from the remaining lung tissue were also trimmed. The number of sections examined ranged from 6 to 47. The mean (SD) number of blocks per patient was 16 (7). The tissue blocks were processed according to standard procedures for the preparation of haematoxylin and eosin stained histological sections and examined microscopically. A histological diagnosis of AAH was made independently by two observers (RN, TY) based on the following 

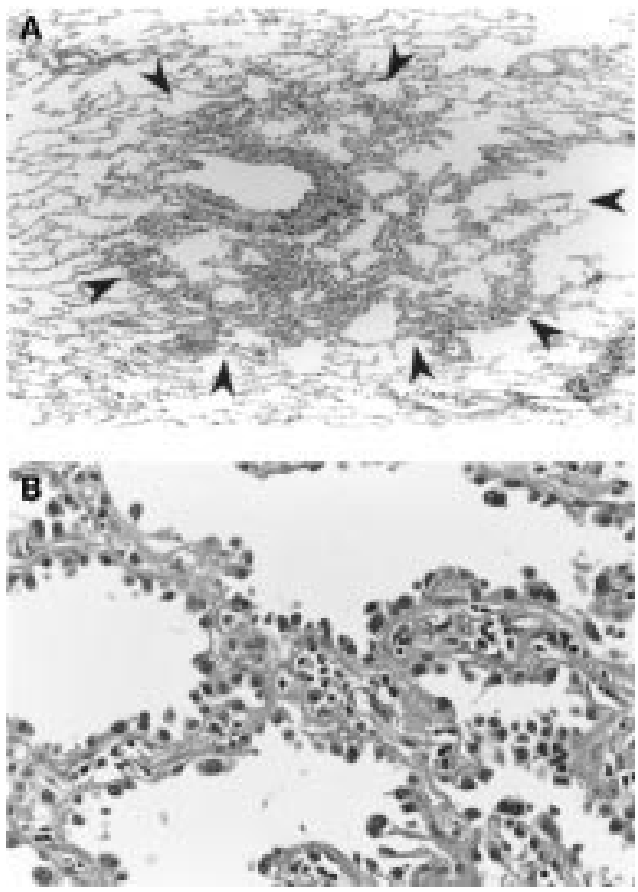

Figure 1 Pathological findings in atypical adenomatous hyperplasia $(A A H)$. (A) The lesion has well defined boundaries (arrowhead) and the alveolar wall shows slight thickening, but there is no central scar formation or collapse. (B) Atypical cuboid to low columnar cells have proliferated along the slightly thickened alveolar wall. Atypical cells in AAH have hyperchromatic nuclei and vague or occasionally prominent nucleoli. Original magnifications $(A) \times 25,(B) \times 50$.

criteria $^{215}{ }^{17-19}:$ (1) lesion with well defined boundaries comprising a single layer of atypical cells without central scar formation or collapse; (2) abundant cytoplasm with cells which often had a rounded or domed appearance resembling type II pneumocytes; (3) atypical cells with hyperchromatic nuclei and vague or occasionally prominent nucleoli, but milder atypia than in adenocarcinoma; (4) the alveolar septa lined by atypical cells were slightly thickened by fibrosis in most instances (fig $1 \mathrm{~A}$ and $\mathrm{B}$ ). Two observers independently examined the specimens and discussed the cases in which their diagnoses differed. Ultimately, the diagnosis was determined based on the above criteria.

The number and location of all AAH lesions and the primary carcinomas were investigated separately in each case. In the 11 cases of central type lung carcinoma the carcinomas were

Table 1 Location of carcinomas and AAHs in each lobe

\begin{tabular}{lllll}
\hline Side & $\begin{array}{l}\text { No. of lobes } \\
\text { examined }\end{array}$ & $\begin{array}{l}\text { No. of } \\
\text { carcinomas }\end{array}$ & $\begin{array}{l}\text { No. of AAH } \\
\text { lesions }\end{array}$ & Frequency (\%)t \\
\hline Right & 167 & 169 & 132 & $41(25)+\dagger$ \\
$\quad$ Upper lobe & 169 & 14 & $6(11)+\dagger$ \\
$\quad$ Middle lobe & 56 & 120 & 61 & $20(18)$ \\
$\quad$ Lower lobe & 110 & 135 & 63 & $35(26)$ \\
Left & & 90 & 41 & $19(19)$ \\
$\quad$ Upper lobe & 137 & 11 & 311 & $121(21)$ \\
$\quad$ Lower lobe & 102 & 554 & &
\end{tabular}

AAH $=$ atypical adenomatous hyperplasia.

^Eleven were classified as central type because they could not be classified to specific lobes.

tFrequency $(\%)=$ number of lobes in which AAH was present per number of lobes examined. ††Statistically significant difference between right upper lobe and middle lobe (OR 2.7; CI 1.1 to 6.0) using logistic regression. classified as central lesions, but the number and location of their AAH lesions were classified as AAH lesions in each lobe in which they were detected. Cases with solitary AAH lesions were assigned to the AAH (+) group. The cases with carcinomas contiguous to $\mathrm{AAH}-$ like lesions without any isolated $\mathrm{AAH}$ were not included in the AAH (+) group. Cases without solitary AAH lesions were assigned to the AAH (-) group. To clarify the clinicopathological characteristics of the cases with multiple AAH lesions we divided the AAH (+) group into a single $\mathrm{AAH}(+)$ group, consisting of cases with one AAH lesion, and a multiple AAH (+) group, consisting of cases with two or more AAH lesions. We statistically analysed the correlation between the AAH groups and the following clinicopathological features: sex, age, smoking status, familial history of malignancy, preceding malignancy, histological type of primary carcinoma, and the number of primary carcinomas. Smoking status was obtained from a questionnaire on smoking habits and patients were classified as never smokers, ex-smokers, or current smokers with an estimate of the number of pack-years. A family history of malignancy and preceding malignancy was obtained from the data from the patient and family interview. We asked whether any first degree relatives (parents, children, and siblings) had a history of malignant disease.

Fisher's exact test, the $\chi^{2}$ test, Student's $t$ test, Mann-Whitney test, and logistic regression were used for the statistical analysis. A p value of 0.05 or less was considered significant.

\section{Results}

A total of $311 \mathrm{AAH}$ lesions were identified in $118(23.2 \%)$ of the 508 surgically resected cases. The mean (SD) number of blocks per patient in the AAH (+) group and AAH (-) group were the same (16 (7)).

Table 1 shows the location of primary lung carcinomas and AAH lesions in the resected lobes. A total of 543 carcinomas were detected in 572 resected lobes. Eleven carcinomas were classified as central lesions according to location. Histologically, the 554 consisted of 362 adenocarcinomas, 133 squamous cell carcinomas, 17 large cell carcinomas, 14 small cell carcinomas, and 28 adenosquamous carcinomas. Carcinomas and AAH lesions were most frequently located in the upper lobes. The frequency of AAH lesions in the right middle lobe was significantly lower than that in the right upper lobe. In six cases of multiple $\mathrm{AAH}$ lesions two or more lobes were resected, and five of the cases were found to have AAH lesions in two or more lobes.

Table 2 shows the number of carcinomas and AAH lesions per case. The mean number of carcinomas per case in the AAH (+) group was significantly higher than that in the AAH (-) group (1.19 v 1.06; $\mathrm{p}=0.001)$ The mean number of AAH lesions per case in all of the cases was 0.61, and in the AAH (+) group it was 2.64 .

Table 3 summarises the relationship between the clinicopathological features of the 508 
Table 2 Number of carcinomas and AAH lesions per case

\begin{tabular}{llllll}
\hline Group & No. of cases & $\begin{array}{l}\text { Total no. of } \\
\text { carcinoma }\end{array}$ & $\begin{array}{l}\text { No. of } \\
\text { carcinoma/case }\end{array}$ & $\begin{array}{l}\text { Total no. of } \\
\text { AAH }\end{array}$ & $\begin{array}{l}\text { No. of } \\
\text { AAH/case }\end{array}$ \\
\hline Total & 508 & 554 & 1.09 & 311 & 0.61 \\
AAH (+) & 118 & 141 & $1.19^{\star}$ & 311 & 2.64 \\
AAH (-) & 390 & 413 & $1.06^{\star}$ & 0 & 0 \\
\hline
\end{tabular}

$\mathrm{AAH}=$ atypical adenomatous hyperplasia

${ }^{\star} \mathrm{p}=0.001$ (Mann-Whitney test).

cases in the AAH groups. The most frequent histological type of primary carcinoma in the AAH (+) group, including cases with both single and multiple AAH lesions, was adenocarcinoma (81.4\%, OR $2.97 ; 95 \%$ CI 1.82 to 4.85$)$. In the multiple $\mathrm{AAH}(+)$ group the frequency of adenocarcinoma was $89.4 \%$, which was higher than that in the AAH $(-)$ group and in the single $\mathrm{AAH}(+)$ group. Multiple primary carcinomas were detected in 35 cases, 16 of which were in the AAH (+) groups (six in the single AAH (+) group and 10 in the multiple AAH (+) group). AAH lesions were detected significantly more frequently in the patients with multiple primary lung carcinoma (OR 3.06 ; $95 \%$ CI 1.56 to 6.00 ). No significant differences in sex, age, and smoking status were observed between the AAH (-) group, the single AAH (+) group, and the multiple AAH (+) group.

Table 4 shows the combinations of histological types of multiple primary lung carcinomas in the $\mathrm{AAH}(-)$ group, the single $\mathrm{AAH}(+)$ group, and the multiple AAH (+) group. All 16 cases in the AAH $(+)$ groups had at least one adenocarcinoma, and all 10 cases in the multiple $\mathrm{AAH}(+)$ group had multiple primary adenocarcinomas.

The incidence of a family history of malignancy, of lung cancer, and preceding malignancy in the three groups is summarised in table 5. There was at least one cancer patient among the first degree relatives in $39 \%$ of the primary lung cancer patients (196 of 508) but

Table 3 Relationship between clinicopathological features and AAH groups

\begin{tabular}{|c|c|c|c|c|}
\hline Features & Total & $A A H(-)$ & $\begin{array}{l}\text { AAH(+) } \\
\text { (single/multiple) }\end{array}$ & OR $(95 \% C I)^{*}$ \\
\hline No of cases & 508 & 390 & $118(71 / 47)$ & \\
\hline \multicolumn{5}{|l|}{ Sex } \\
\hline Male & 324 & 257 & $67(38 / 29)$ & \multirow[t]{2}{*}{1.47 (0.97 to 2.24$)$} \\
\hline Female & 184 & 133 & $51(33 / 18)$ & \\
\hline \multicolumn{5}{|l|}{ Age (years) } \\
\hline$\geqslant 65$ & 252 & 193 & $59(38 / 21)$ & \multirow[t]{2}{*}{$1.02(0.68$ to 1.54$)$} \\
\hline$<65$ & 256 & 197 & $59(33 / 26)$ & \\
\hline \multicolumn{5}{|l|}{ Smoking status } \\
\hline Never smokers & 167 & 127 & $40(26 / 14)$ & \multirow[t]{8}{*}{$1.06(0.69$ to 1.64$)$} \\
\hline Smokers & 341 & 263 & $78(45 / 33)$ & \\
\hline Ex-smokers & 128 & 100 & $28(16 / 12)$ & \\
\hline$\leqslant 20$ pack-years smoked & 29 & 19 & $10(4 / 6)$ & \\
\hline$>20$ pack-years smoked & 99 & 81 & $18(12 / 6)$ & \\
\hline Current smokers & 213 & 163 & $50(29 / 21)$ & \\
\hline$\leqslant 20$ pack-years smoked & 17 & 11 & $6(4 / 2)$ & \\
\hline$>20$ pack-years smoked & 196 & 152 & $44(25 / 19)$ & \\
\hline \multicolumn{5}{|l|}{ Histology† } \\
\hline Adenocarcinoma & 328 & 232 & $96(54 / 42)$ & \multirow[t]{6}{*}{$2.97(1.82$ to 4.85$)$} \\
\hline Non-adenocarcinoma & 180 & 158 & $22(17 / 5)$ & \\
\hline Squamous & 122 & 110 & $12(9 / 3)$ & \\
\hline Large cell & 17 & 15 & $2(1 / 1)$ & \\
\hline Small cell & 13 & 12 & $1(1 / 0)$ & \\
\hline Adenosquamous & 28 & 21 & $7(6 / 1)$ & \\
\hline \multicolumn{5}{|l|}{ No. of lung carcinoma } \\
\hline Single & 473 & 371 & $102(65 / 37)$ & \multirow[t]{2}{*}{$3.06(1.56$ to 6.00$)$} \\
\hline Multiple & 35 & 19 & $16(6 / 10)$ & \\
\hline
\end{tabular}

AAH $=$ atypical adenomatous hyperplasia

${ }^{\star} \mathrm{AAH}(-)$ group $v$ AAH $(+)$ groups (logistic regression).

tIn cases of multiple carcinoma the histological type of the largest tumour was used.
Table 4 Combination of multiple primary carcinomas $(n=35)$ and $A A H$ groups

\begin{tabular}{|c|c|c|c|c|}
\hline \multirow[b]{3}{*}{$\begin{array}{l}\text { No. of } \\
\text { carcinomas }\end{array}$} & \multirow[b]{3}{*}{$\begin{array}{l}\text { Histological } \\
\text { combination }\end{array}$} & \multicolumn{3}{|c|}{$A A H$ group } \\
\hline & & \multirow[b]{2}{*}{$A A H(-)$} & \multicolumn{2}{|c|}{$A A H(+)$} \\
\hline & & & Single & Multiple \\
\hline \multirow[t]{5}{*}{2} & $\mathrm{Ad} / \mathrm{Ad}$ & 5 & 4 & 7 \\
\hline & $\mathrm{Ad} / \mathrm{Sq}$ & 5 & 1 & 0 \\
\hline & $\mathrm{Sq} / \mathrm{Sq}$ & 4 & 0 & 0 \\
\hline & $\mathrm{Ad} / \mathrm{Sm}$ & 1 & 0 & 0 \\
\hline & $\mathrm{Sq} / \mathrm{Sm}$ & 1 & 0 & 0 \\
\hline \multirow[t]{2}{*}{3} & $\mathrm{Ad} / \mathrm{Ad} / \mathrm{Ad}$ & 1 & 0 & 1 \\
\hline & $\mathrm{La} / \mathrm{Sq} / \mathrm{Sq}$ & 1 & 0 & 0 \\
\hline 4 & $\mathrm{Ad} / \mathrm{Ad} / \mathrm{Ad} / \mathrm{Ad}$ & 1 & 1 & 2 \\
\hline
\end{tabular}

$\mathrm{AAH}=$ atypical adenomatous hyperplasia; $\mathrm{Ad}=$ adenocarcinoma; $\mathrm{Sq}=$ squamous cell carcinoma; $\mathrm{La}=$ large cell carcinoma; $\mathrm{Sm}=$ small cell carcinoma

Table 5 Relationship between familial history, preceding malignancy and $A A H$ groups

\begin{tabular}{|c|c|c|c|c|}
\hline Features & Total & $A A H(-)$ & $\begin{array}{l}\text { AAH }(+) \\
\text { (single/multiple) }\end{array}$ & OR $(95 \% C I) \dagger$ \\
\hline \multicolumn{5}{|c|}{ Family history of malignancy } \\
\hline$(+)$ & 196 & 147 & $49(30 / 19)$ & \multirow[t]{2}{*}{$1.17(0.77$ to 1.79$)$} \\
\hline$(-)$ & 312 & 243 & $69(41 / 28)$ & \\
\hline \multicolumn{5}{|c|}{ Family history of lung carcinoma } \\
\hline$(+)$ & 40 & 26 & $14(7 / 7)$ & \multirow[t]{2}{*}{$1.88(0.96$ to 3.71$)$} \\
\hline$(-)$ & 468 & 364 & $104(64 / 40)$ & \\
\hline \multicolumn{5}{|c|}{ Preceding malignancy } \\
\hline$(+)$ & 41 & 27 & $14\left(3 / 11^{\star}\right)$ & \multirow[t]{2}{*}{$1.81(0.92$ to 3.55$)$} \\
\hline$(-)$ & 467 & 363 & $104\left(68 / 36^{\star}\right)$ & \\
\hline
\end{tabular}

$\mathrm{AAH}=$ atypical adenomatous hyperplasia.

* Statistically significant compared with AAH (-) group (OR $4.11 ; 95 \%$ CI 1.98 to 8.53 ) and single $\mathrm{AAH}(+)$ group (OR $6.93 ; 95 \%$ CI 2.08 to 23.06$)$ by logistic regression.

†AAH (-) group $v$ AAH (+) groups by logistic regression.

there was no significant correlation between a family history of malignancy and the presence of AAH. In 40 of the 196 cases there was a family history of lung cancer; 14 of the cases were in the $\mathrm{AAH}(+)$ group and 26 in the $\mathrm{AAH}$ $(-)$ group but there was no significant correlation between a family history of lung cancer and the AAH groups. In contrast to the family history of malignancy, 11 cases $(23.4 \%)$ in the multiple $\mathrm{AAH}(+)$ group had a preceding malignancy of their own. A significant correlation between a history of preceding malignancy and multiple $\mathrm{AAH}$ lesions was observed. The preceding malignancies in the 11 cases in the multiple $\mathrm{AAH}(+)$ group consisted of two cases of gastric cancer, three cases of colorectal cancer, and one case each of cancer of the liver, breast, urinary bladder, thyroid, head and neck, and malignant lymphoma. Most of the preceding malignancies had been diagnosed and cured at other hospitals, so we were unable to confirm the histological type of the preceding malignancy.

\section{Discussion}

We have analysed 508 surgically resected cases of lung cancer, with or without solitary AAH lesions; $118(23.2 \%)$ of the 508 cases were found to have solitary AAH lesions. We have previously reported AAH lesions in 16 of 241 elderly necropsy cases $(6.6 \%)$ and found them to be more frequent in 12 of 118 patients with a malignant neoplasm $(11.1 \%) .{ }^{19}$ In this study the occurrence of $\mathrm{AAH}$ lesions in lungs surgically resected for cancer was higher than in the previous study, suggesting that AAH occurs more frequently in lung cancer patients. 
In this study the clinicopathological results clearly show a close correlation between the presence of AAH lesions and both adenocarcinoma and the occurrence of multiple primary cancers. Our findings are consistent with the hypothesis that AAH is a precursor of adenocarcinoma of the lung. ${ }^{121314}$ They are important because they confirm the concept of the progression of multistep carcinogenesis through AAH to adenocarcinoma of the lung. We and other investigators have also provided evidence of a sequence from $\mathrm{AAH}$ to adenocarcinoma. We previously reported the monoclonal nature of $\mathrm{AAH}$ based on an $\mathrm{X}$ chromosome-linked polymorphic marker, the human androgen receptor gene (HUMARA). ${ }^{20}$ Immunohistochemical studies of carcinoembryonic antigen (CEA) and the p53 gene product combined with molecular genetical analysis of the p53 gene have shown that the immunohistochemical and genetic abnormalities frequently observed in adenocarcinoma are also detected in AAH lesions. ${ }^{40-23}$ These findings, combined with the results of the present study, strongly support the hypothesis that an $\mathrm{AAH}$ to adenocarcinoma sequence is one of the carcinogenetic pathways in the lung.

The clinical management of AAH lesions has not yet been determined. In this study we have shown that AAH lesions are closely associated with multiple adenocarcinoma and that they are evenly distributed throughout the whole lung, although AAH lesions were observed less frequently in the middle lobe than in the other lobes. These findings indicate the possibility that the risk of metachronous lung adenocarcinoma is higher in patients with multiple AAH lesions. In fact, we encountered one case of metachronous primary lung adenocarcinoma in which there were multiple adenocarcinomas and multiple AAH lesions. Thus, close and precise follow up is necessary for patients with multiple AAH lesions.

To identify patients with multiple AAH lesions we examined a mean of 16 (7) blocks per patient. Chapman et al also reported finding $\mathrm{AAH}$ lesions in about $30 \%$ of patients with adenocarcinoma of the lung by examining 1-6 random sampling blocks of lung parenchyma. $^{24}$ These data, combined with the findings in our present study, suggest that careful observation of all surfaces of sliced specimens with a loupe and stereoscopic microscope is important to detect these small lesions.

A family history of malignancy and of lung cancer were not significantly correlated with the AAH (-) group, single AAH (+) group, or multiple AAH (+) group. On the other hand, the cases with multiple AAH lesions were shown to have a higher frequency of preceding malignancy throughout the whole body, although the organ affected by the preceding malignancy was not specifically correlated with AAH. This suggests that patients with multiple $\mathrm{AAH}$ lesions may have a predisposition to malignant neoplasms. In the near future it will be possible to diagnose AAH lesions preoperatively by advanced radiological imaging. Precise whole body examinations will therefore be possible in patients with multiple AAH lesions. However, the process of progression of AAH remains unclear. Further prospective follow up studies will be needed to establish a method of management for patients with AAH.

This work was supported in part by a grant-in-aid for Cancer Research from the Ministry of Health and Welfare, Japan. The authors would like to thank Dr Satoshi Sasaki (Epidemiology
and Biostatistics Division, National Cancer Center Research Institute East) for his technical support in statistical analyses.

1 Carey FA, Wallace WA, Fergusson RJ, et al. Alveolar atypical hyperplasia in association with primary pulmonary adenocarcinoma: a clinicopathological study of 10 cases. Thorax 1992;47:1041-3.

2 Kodama T, Biyajima S, Watanabe S, et al. Morphometric study of adenocarcinomas and hyperplastic epithelial lesions in the peripheral lung. Am f Clin Pathol 1986;85: $146-51$

3 Colby TV, Wistuba, II, Gazdar A. Precursors to pulmonary neoplasia. Adv Anat Pathol 1998;5:205-15.

4 Kerr KM, Carey FA, King G, et al. Atypical alveolar hyperplasia: relationship with pulmonary adenocarcinoma, p53, and c-erbB-2 expression. F Pathol 1994;174:249-56.

5 Miller RR. Bronchioloalveolar cell adenomas. Am f Surg Pathol 1990;14:904-12.

6 Rao SK, Fraire AE. Alveolar cell hyperplasia in association with adenocarcinoma of lung. Mod Pathol 1995;8:165-9.

7 Kurasono Y, Ito T, Kameda Y, et al. Expression of cyclin D1, retinoblastoma gene protein, and p16 MTS1 protein in atypical adenomatous hyperplasia and adenocarcinoma of the lung. An immunohistochemical analysis. Virchows Arch 1998;432:207-15.

8 Kitamura H, Kameda Y, Ito T, et al. Cytodifferentiation of atypical adenomatous hyperplasia and bronchioloalveolar lung carcinoma: immunohistochemical and ultrastructural studies. Virchows Arch 1997;431:415-24.

9 Westra WH, Baas IO, Hruban RH, et al. K-ras oncogene activation in atypical alveolar hyperplasias of the human lung. Cancer Res 1996;56:2224-8.

10 Cooper CA, Carby FA, Bubb VJ, et al. The pattern of K-ras mutation in pulmonary adenocarcinoma defines a new pathway of tumour development in the human lung. $\mathcal{F}$
Pathol 1997;181:401-4.

11 Sone S, Takashima S, Li F, et al. Mass screening for lung cancer with mobile spiral computed tomography scanner. Lancet 1998;351:1242-5.

12 Weng S, Tsuchiya E, Satoh Y, et al. Multiple atypical adenomatous hyperplasia of type II pneumonocytes and bronchiolo-alveolar carcinoma. Histopathology 1990;16: 101-3.

13 Takigawa N, Segawa Y, Nakata M, et al. Clinical investigation of atypical adenomatous hyperplasia of the lung. Lung Cancer 1999;25:115-21.

14 Weng SY, Tsuchiya E, Kasuga T, et al. Incidence of atypical bronchioloalveolar cell hyperplasia of the lung: relation to histological subtypes of lung cancer. Virchows Arch A Pathol Anat Histopathol 1992;420:463-71.

15 Suzuki K, Nagai K, Yoshida J, et al. The prognosis of resected lung carcinoma associated with atypical adenomaresected lung carcinoma associated with atypical adenomadifferentiated adenocarcinoma associated with atypical differentiated adenocarcinoma associated with atypical Cancer 1997;79:1521-6.

16 World Health Organization. Histological typing of lung tumors. 2nd ed. Genova: World Health Organization, 1981.

17 Mori M, Chiba R, Takahashi T. Atypical adenomatous hyperplasia of the lung and its differentiation from adenocarcinoma. Characterization of atypical cells by morphometry and multivariate cluster analysis. Cancer 1993;72:2331-40.

18 Yokozaki M, Kodama T, Yokose T, et al. Differentiation of atypical adenomatous hyperplasia and adenocarcinoma of the lung by use of DNA ploidy and morphometric analysis. Mod Pathol 1996;9:1156-64.

19 Yokose T, Ito Y, Ochiai A. High prevalence of atypical adenomatous hyperplasia of the lung in autopsy specimens from elderly patients with malignant neoplasms. Lung Cancer 2000;29:125-130

20 Niho S, Yokose T, Suzuki K, et al. Monoclonality of atypical adenomatous hyperplasia of the lung. Am $f$ Pathol 1999;154:249-54

21 Kitamura H, Kameda Y, Nakamura N, et al. Proliferative potential and p53 overexpression in precursor and early stage lesions of bronchioloalveolar lung carcinoma. $A m \mathcal{F}$ Pathol 1995;146:876-87.

22 Kitamura H, Kameda Y, Nakamura N, et al. Atypical adenomatous hyperplasia and bronchoalveolar lung carcinoma. Analysis by morphometry and the expressions of p53 and carcinoembryonic antigen. Am $\mathcal{F}$ Surg Pathol 1996; 20:553-62.

23 Slebos RJ, Baas IO, Clement MJ, et al. p53 alterations in atypical alveolar hyperplasia of the human lung. Hum

24 Chapman AD, Kerr KM. The association between atypical adenomatous hyperplasia and primary lung cancer. $\mathrm{Br} f$ Cancer 2000;83:632-6. 